\title{
The Removal of Chromium(VI) from Aqueous Solution by Amine-Functionalized Zeolite: Kinetics, Thermodynamics, and Equilibrium Study
}

\author{
Shirendev Nasanjargal1, Bat-Amgalan Munkhpurev², Naoki Kano ${ }^{3}{ }^{\circledR}$, Hee-Joon Kim³, \\ Yunden Ganchimeg ${ }^{*}$ \\ ${ }^{1}$ Department of Chemical Engineering, School of Applied Sciences, Mongolian University of Sciences and Technology, \\ Ulaanbaatar, Mongolia \\ ${ }^{2}$ Graduate School of Science and Technology, Niigata University, Niigata, Japan \\ ${ }^{3}$ Department of Chemistry and Chemical Engineering, Faculty of Engineering, Niigata University, Niigata, Japan \\ Email: ^ganchimeg.yu@must.edu.mn
}

How to cite this paper: Nasanjargal, S., Munkhpurev, B.-A., Kano, N., Kim, H.-J. and Ganchimeg, Y. (2021) The Removal of Chromium(VI) from Aqueous Solution by Amine-Functionalized Zeolite: Kinetics, Thermodynamics, and Equilibrium Study. Journal of Environmental Protection, 12, 654-675. https://doi.org/10.4236/jep.2021.129040

Received: August 19, 2021

Accepted: September 26, 2021

Published: September 29, 2021

Copyright $\odot 2021$ by author(s) and Scientific Research Publishing Inc. This work is licensed under the Creative Commons Attribution-NonCommercial International License (CC BY-NC 4.0). http://creativecommons.org/licenses/by-nc/4.0/ cc) (i) (9) Open Access

\begin{abstract}
In this study, the removal of $\mathrm{Cr}(\mathrm{VI})$ from aqueous solution by modified zeolite with 3-aminopropyltriethoxysilane was investigated. The effect of various parameters such as $\mathrm{pH}$, contact time, temperature, initial concentration of $\mathrm{Cr}(\mathrm{VI})$ ion, common cations, and anions on the adsorption of $\mathrm{Cr}(\mathrm{VI})$ was studied. The modified zeolite was characterized by following instrumental analysis of XRD, SEM/EDS, BET, and FT-IR. Based on calculated thermodynamic parameters values $\left(\Delta G^{0}<0, \Delta H^{0}>0\right.$, and $\left.\Delta S^{0}>0\right)$ and kinetic properties of the adsorption of $\mathrm{Cr}(\mathrm{VI})$ by modified zeolite, it was concluded that the ratelimiting step of the process is a second-order chemical reaction. The results of the adsorption isotherm study confirmed that the adsorption follows the Langmuir isotherm model. The maximum adsorption capacity was $13.5 \mathrm{mg} / \mathrm{g}$.
\end{abstract}

\section{Keywords}

Adsorption Mechanism, Adsorption Thermodynamics, Kinetics, Isotherm

\section{Introduction}

Water containing heavy metals such as chromium, lead, copper, mercury, and nickel has created problems for living organisms and the environment. It also causes cancer in humans [1] [2] [3]. Chromium is one of the most toxic and soluble heavy metals. When chromium ions enter the human body, they enter the 
bloodstream and damage the liver, kidney, lung, and brain cells and lead to cancer [4]. Each method to remove heavy metals from the polluted water with heavy metals (chemical precipitation, ion exchange, precipitation, membrane separation, and reverse osmosis and adsorption) has its advantages and disadvantages. An adsorption method can be more selective and efficient than the other methods if the cost of the adsorbent is reduced [5].

Mongolia has a significant resource of lignite, zeolite, and other aluminosilicate rocks that can be used as adsorbents for wastewater treatment. These materials, especially zeolite minerals can adsorb heavy metal ions selectively due to the following advantages, porous structure, ion exchangeable character, and reusability. In the adsorption method, Mongolian natural zeolite has been studied for the removal of heavy metals by several researchers. Among them, Ts. Bolortamir, et al. [6] studied the removal of hexavalent chromium from tannery wastewater using natural zeolite from Tsagaan Tsav and Urgun deposits in Dornogovi Province of Mongolia. They reported that zeolite modified with barium chloride adsorb hexavalent chromium favorably, and fractional removal of higher (over 0.9) than natural zeolite. R. Egashira, et al. [7] investigated the removal of $\mathrm{Cu}, \mathrm{Zn}$ and, $\mathrm{Mn}$ from mine wastewater using natural zeolite from Tsagaan Tsav deposit in Dornogovi Province of Mongolia, and studied batch equilibrium adsorptions of the heavy metals. Also, $\mathrm{Cs}$ and $\mathrm{Sr}$ adsorption on the clinoptilolite-rich zeolite from three different deposits located in the southwest of Mongolia was investigated [8]. Furthermore, the ability of natural minerals from Tushleg and Tsagaan Tsav deposits in Dornogovi Province of Mongolia as adsorbents was investigated [9], and it was shown that the order of heavy metal selectivity was $\mathrm{Pb}^{2+}>>\mathrm{Zn}^{2+}>\mathrm{Cd}^{2+}$. Moreover, they confirmed that modification with magnesium oxide is more effective on zeolite from Tushleg deposit for enhancing arsenic(V) adsorption from the aqueous solution.

The purpose of this work is to develop an adsorbent for the removal of chromium(VI) from an aqueous solution. The natural zeolite produced in Dornogovi province (Tsagaantsav Mine, the deposit is possible to produce 4.8 million tonnes of zeolite minerals) of Mongolia has been selected as adsorbent and it has been modified by a silicon-organic monomer (3-aminopropyltriethoxysilane), which contains active functional groups, low toxicity, and simple structure [10]. The modified zeolite was characterized by XRD, BET, SEM, and FT-IR. The dependences of the variable parameters for the optimal conditions of the process are determined. The thermodynamics, kinetics, and isotherms were studied to explain the adsorption mechanism.

\section{Experimental Section}

\subsection{Chemicals and Reagents}

All chemicals and reagents including, 3-aminopropyltriethoxysilane (APTES), toluene (98\%), $\mathrm{NaOH}\left(>98 \%\right.$, pellets), $\mathrm{HNO}_{3}$, and $\mathrm{HCl}(>36 \%)$ were analytical grades. The standard solutions of $\mathrm{Cr}(\mathrm{VI})$ were prepared by dissolving $\mathrm{K}_{2} \mathrm{CrO}_{7}$ 
into redistilled water.

\subsection{Modification of Natural Zeolite}

The modification experiment was performed in two main stages: 1) Pretreatment of natural zeolite sample and 2) modification with silicon-organic monomer, 3-aminopropyltriethoxysilane. The first stage: The sample was crushed and sieved to a particle size range of $0.45-0.3 \mathrm{~mm}$. The natural zeolite sample was heated in a muffle furnace at $700^{\circ} \mathrm{C}$ for 3 hours to activate the surface. The temperature of $700^{\circ} \mathrm{C}$ had chosen based on chemical and mineral composition of the natural zeolite [11]. Then the activated sample was washed three times with hydrochloric acid solution (5\%) and distilled water, respectively, to remove fine powders and contaminants, then dried at $110^{\circ} \mathrm{C}$ for 2 hours [12]. At modification stage: $10 \mathrm{~g}$ of pretreated zeolite was added into $100 \mathrm{ml}$ of 3-aminopropyltryethoxycylane solution (30\% (vol) in toluene) and stirred for 3 hours at a temperature of $50^{\circ} \mathrm{C}$. Then, the mixture was filtered, the solid residue was washed several times with distilled water and dried in the oven for 4 hours at $110^{\circ} \mathrm{C}$. The modified zeolite was cooled on a vacuum desiccator for further use [13].

\subsection{Characterization of Natural and Modified Zeolite}

The surface morphology and chemical composition of the natural and modified zeolite were investigated using a scanning electron microscope (SEM) equipped with an X-ray energy dispersive detector (EDS), JCM-6000, JED-2300, JEOL, and TM1000-Hitachi. The Brunauer Emmet Teller (BET) method with nitrogen gas adsorption/desorption test was applied to measure the surface area of the samples using TriStarII 3020, Micromeritics. The samples were analyzed by an X-ray diffractometer (XRD), D2 Phaser, Bruker to determine mineral composition. The Fourier Transform Infrared Spectroscopy, FT-IR 4200, JASCO was used to identify the functional groups of the samples.

\subsection{Adsorption Experiment}

The batch experiments were carried out by stirring $0.1 \mathrm{~g}$ of modified zeolite with $50 \mathrm{ml}$ of adsorbate solution of $\mathrm{Cr}(\mathrm{VI})$ in a temperature-controlled shaker (PC-620D, CORNING) for various times (0.5 - 6 hours) with a rotational speed of $100 \mathrm{rpm}$. Then the suspension was filtered, and an aliquot of $1 \mathrm{ml}$ of filtrate was taken for $\mathrm{Cr}$ (VI) determination by spectrophotometer (U2910, Hitachi) at the wavelength of $540 \mathrm{~nm}$. The 1,5-diphenilcarbazide was used as a complexing reagent. The adsorption capacity was calculated by the following equation:

$$
q=\left(C_{0}-C_{e}\right) \times \frac{V}{m}
$$

where, $q$ is the adsorption capacity, $\mathrm{mg} / \mathrm{g} ; C_{0}$ and $C_{e}$ are initial and equilibrium concentrations of $\mathrm{Cr}(\mathrm{VI}), \mathrm{mg} / \mathrm{l} ; m$ is the mass of modified zeolite, $\mathrm{g}$; $V$ is the volume of solution, $\mathrm{ml}$. 


\subsection{Desorption Experiment}

For the desorption and regeneration study, $0.1 \mathrm{~g}$ modified zeolite was contacted with $50 \mathrm{ml}$ of $50 \mathrm{mg} / \mathrm{l} \mathrm{Cr}(\mathrm{VI})$ solution at $\mathrm{pH}=3$. After 3 hours of adsorption, exhausted adsorbent was carefully separated from the solution and washed thoroughly. Then desorption experiments were performed for 3 hours, $50 \mathrm{ml}$ solutions of $\mathrm{HNO}_{3}$ with different concentrations $(0.05-0.4 \mathrm{M})$ were used to desorb $\mathrm{Cr}(\mathrm{VI})$ from the modified zeolite adsorbent. At the end of each adsorptiondesorption cycle, the modified zeolite was washed with redistilled water. The desorbed total $\mathrm{Cr}$ concentration was determined by spectrophotometer (U2910, Hitachi). The desorption efficiency of $\mathrm{Cr}$ was calculated as the ratio of the desorbed amount to the adsorbed amount.

\section{Result and Discussion}

\subsection{Effect of $\mathrm{pH}$ on the Adsorption of $\mathrm{Cr}(\mathrm{VI})$}

To investigate the effect of the $\mathrm{pH}$ of the solution on the adsorption capacity of both natural and modified zeolites for $\mathrm{Cr}(\mathrm{VI})$, the $\mathrm{pH}$ of the solution was varied from 2 to 7 (Figure 1) using $\mathrm{HNO}_{3}$ and $\mathrm{NaOH}$ solutions. The adsorption of $\mathrm{Cr}(\mathrm{VI})$ is highly dependent on the $\mathrm{pH}$ of the solution, which affects the surface charge of the adsorbent, the degree of ionization, and the chemical speciation of the chromium species. Chromate anion exists as $\mathrm{HCrO}_{4}^{-}$as $\mathrm{CrO}_{4}^{2-}$ in the range of $\mathrm{pH} 2-6.5$ and $\mathrm{pH} 8$ - 10 (Figure 2).

Figure 1 shows that the adsorption capacity decreases with the increasing value of $\mathrm{pH}$. It means that the electrostatic attraction between protonated modified zeolite surface and chromate anions affects the adsorption capacity. At a lower $\mathrm{pH}$ value, the modified zeolite surface groups were protonated, at a higher

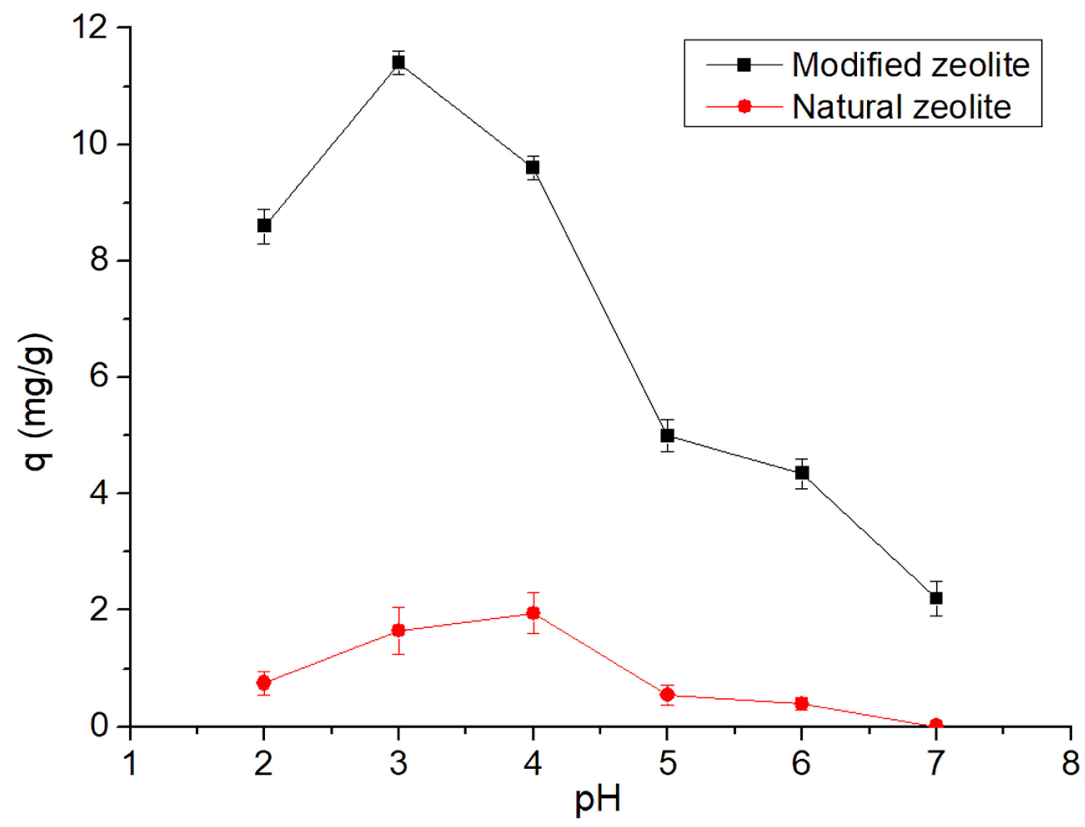

Figure 1. Effect of $\mathrm{pH}$ on the adsorption of $\mathrm{Cr}(\mathrm{VI})\left(C_{0}=50 \mathrm{mg} / \mathrm{l}, T=25^{\circ} \mathrm{C}, t=2 \mathrm{~h}\right)$. 


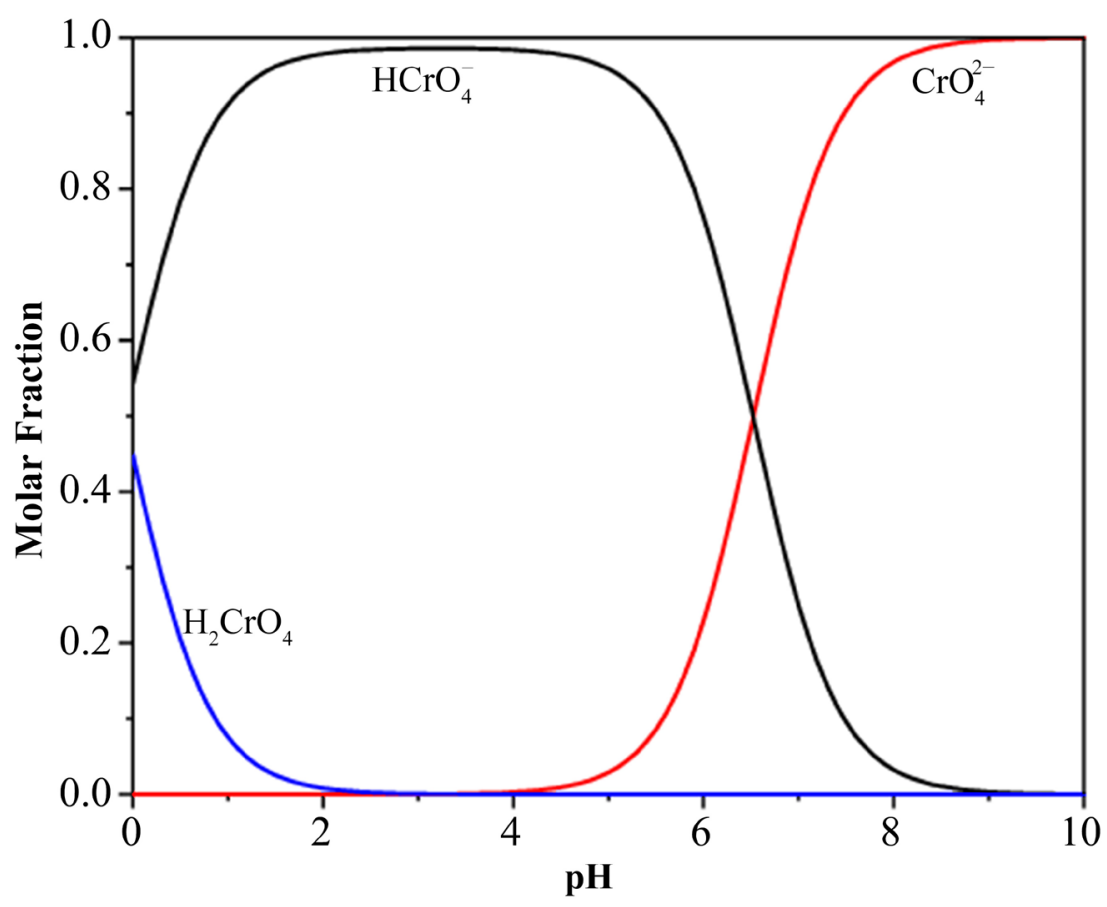

Figure 2. Relative distribution diagram of $\mathrm{Cr}(\mathrm{VI})$ species in the aqueous solution.

$\mathrm{pH}$ value proton dissociation occurs, and consequently, deprotonated surface repulses the chromate anion. Based on this experiment, it is assumed that the 3-aminopropyltrimethoxysilane can react with the - $\mathrm{OH}$ groups on natural zeolite and thus form an amino-functionalized zeolite. The amino group of modified zeolite can have ionized in acidic conditions and thereby become positively charged (Scheme 1). The modified zeolite and $\mathrm{HCrO}_{4}^{-}$were conducted by Scheme 2.

The maximum adsorption capacity of modified zeolite is more than natural zeolite and reaches $11.4 \mathrm{mg} / \mathrm{g}$ at $\mathrm{pH}=3$, where the predominant species is $\mathrm{HCrO}_{4}^{-}$for $\mathrm{Cr}(\mathrm{VI})$. Hence, $\mathrm{pH} 3$ was taken for further experiments.

\subsection{Effect of Initial Concentration and Time}

The modified zeolite was used in this investigation, the result of the previous experiment (Figure 1) confirmed that natural zeolite was modified successfully. The investigation for the effect of time was carried out at $\mathrm{pH}=3$, using solutions of $\mathrm{Cr}(\mathrm{VI})$ with initial concentrations of $10,25,50$, and $100 \mathrm{mg} / \mathrm{l}$. The result shows that the increase of the adsorption rate is rapid in the first 30 minutes and slow during the next 2.5 hours, then it becomes constant (Figure 3 ). The first stage may attribute to electrostatic attractions between the protonated surface of the adsorbent and $\mathrm{HCrO}_{4}^{-}$. The second stage may attribute to a conversion of the electrostatic bonds to chemical bonds. The maximum adsorption capacity was increased from $4.2-12.2 \mathrm{mg} / \mathrm{g}$ when the initial concentration increased from 10 to $100 \mathrm{mg} / \mathrm{l}$. It may be related to the increase of the driving force of the concentration gradient. 


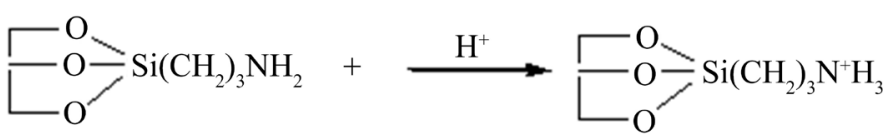

Scheme 1. Surface protonation of modified zeolite in acidic condition.

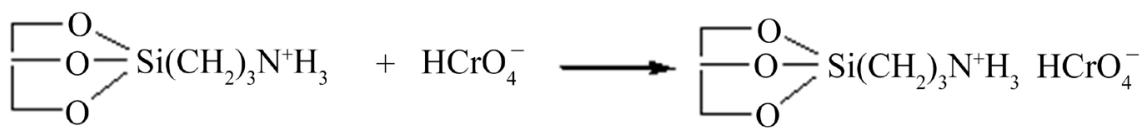

Scheme 2. Interaction between surface of modified zeolite and $\mathrm{HCrO}_{4}^{-}$.

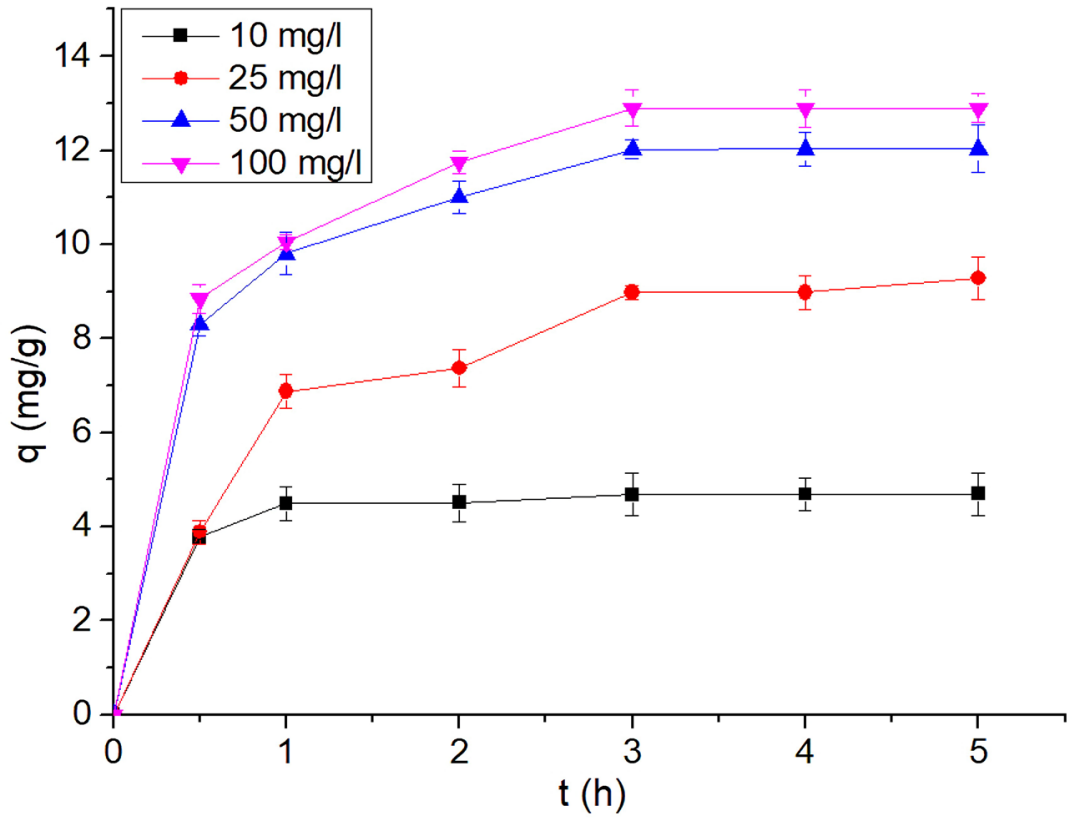

Figure 3. Effect of initial concentration and time ( $\mathrm{pH}=3, T=25^{\circ} \mathrm{C}, n=100 \mathrm{rpm}$ ).

\subsection{Effect of Temperature}

Temperatures of $25^{\circ} \mathrm{C}, 35^{\circ} \mathrm{C}, 45^{\circ} \mathrm{C}$, and $55^{\circ} \mathrm{C}$ were chosen to study the effect of temperature on the adsorption. The experiment was performed at $\mathrm{pH} 3$ using the solution with the initial concentration of $50 \mathrm{mg} / \mathrm{l}$. As shown in Figure 4, the adsorption capacity increases with increasing temperature, which indicates adsorption reaction is endothermic.

The higher temperature may affect the rate of chemical interaction between $\mathrm{HCrO}_{4}^{-}$and adsorbent, resulting in the enhancement of the number of elastic collisions. The temperature of $45^{\circ} \mathrm{C}$ was chosen for the next isotherm experiment due to the difference in adsorption capacity was low $(\Delta q=0.15 \mathrm{mg} / \mathrm{g})$ when temperature increased from $45^{\circ} \mathrm{C}$ to $55^{\circ} \mathrm{C}$.

\subsection{Effect of Competitive Anions}

To investigate an effective competitive anion such as $\mathrm{NO}_{3}^{-}, \mathrm{Cl}^{-}, \mathrm{SO}_{4}^{2-}, \mathrm{SO}_{3}^{2-}$, and $\mathrm{CH}_{3} \mathrm{COO}^{-}$on the adsorption capacity, $\mathrm{NaNO}_{3}, \mathrm{NaCl}, \mathrm{Na}_{2} \mathrm{SO}_{4}, \mathrm{Na}_{2} \mathrm{SO}_{3}$, and $\mathrm{NaCH}_{3} \mathrm{COO}$ were added to $\mathrm{Cr}(\mathrm{VI})$ solution with a concentration of $50 \mathrm{mg} / \mathrm{l}$. The 


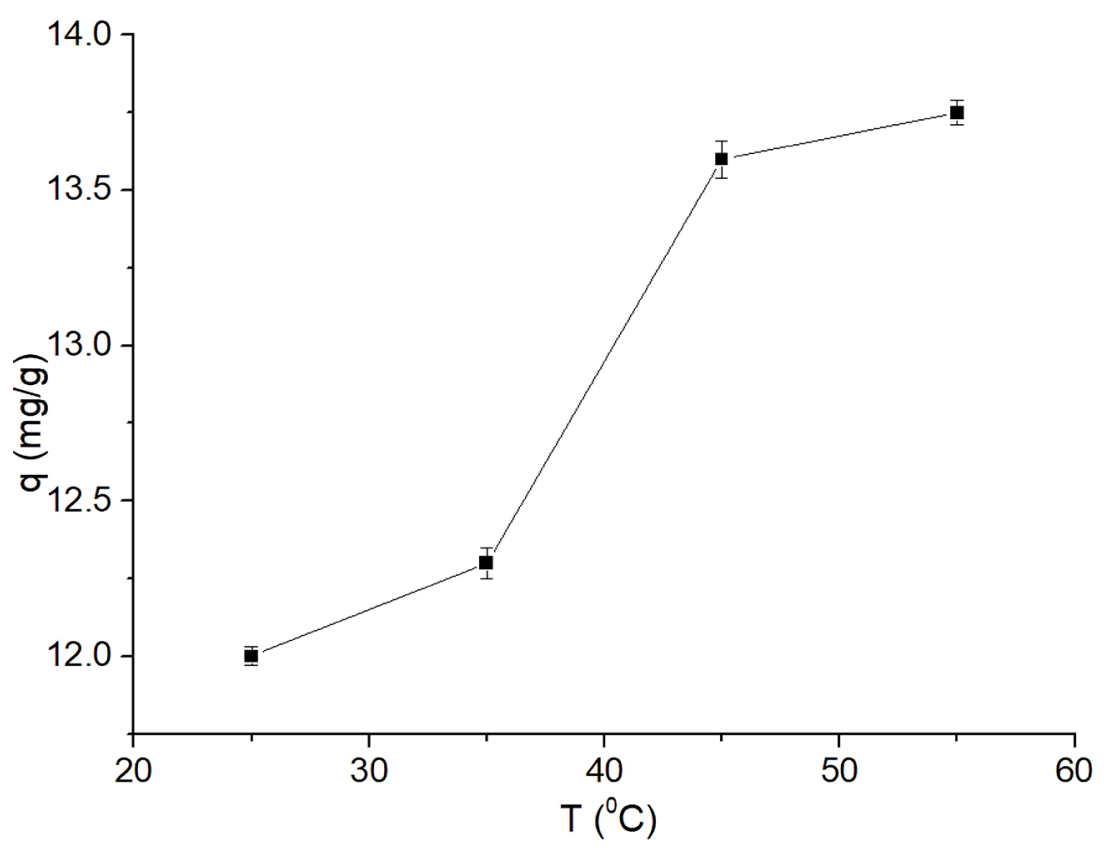

Figure 4. Effect of temperature ( $\left.C_{0}=50 \mathrm{mg} / \mathrm{l}, \mathrm{pH}=3, t=3 \mathrm{~h}, n=100 \mathrm{rpm}\right)$.

concentration of the anions was $10 \mathrm{mg} / \mathrm{l}$ and $20 \mathrm{mg} / \mathrm{l}$. The adsorption capacity decreased significantly while added $\mathrm{NaNO}_{3}$ to $\mathrm{Cr}(\mathrm{VI})$ solution. Therefore, result of the effect of other competitive anions on the adsorption of $\mathrm{Cr}(\mathrm{VI})$ is shown in Figure 5.

The adsorption capacity decreased by $0.67 \%$ and $1.9 \%$ for $\mathrm{Cl}^{-}, 1.08 \%$ and $1.91 \%$ for $\mathrm{SO}_{4}^{2-}, 1.50 \%$ and $2.74 \%$ for $\mathrm{SO}_{3}^{2-}, 1.08 \%$ and $2.33 \%$ for $\mathrm{CH}_{3} \mathrm{COO}^{-}$, respectively. The order of adsorption capacity decreasing in the presence of the anions was $\mathrm{Cl}^{-}<\mathrm{SO}_{4}^{2-} \approx \mathrm{CH}_{3} \mathrm{COO}^{-}<\mathrm{SO}_{3}^{2-}$ and $\mathrm{Cl}^{-} \approx \mathrm{SO}_{4}^{2-}<\mathrm{CH}_{3} \mathrm{COO}^{-}<\mathrm{SO}_{3}^{2-}$ for the anion concentration of $10 \mathrm{mg} / \mathrm{l}$ and 20 $\mathrm{mg} / \mathrm{l}$, respectively. The adsorption capacity was decreased with a low amount when $\mathrm{Cl}^{-}, \mathrm{SO}_{4}^{2-}, \mathrm{SO}_{3}^{2-}$, and $\mathrm{CH}_{3} \mathrm{COO}^{-}$were present. It indicates the high affinity of modified zeolite to bind to $\mathrm{Cr}$.

\subsection{Effect of Competitive Cations}

To investigate an effect common cations, the experiment conducted under optimized $\mathrm{pH}(\mathrm{pH}=3)$, contact time (i.e., 3 hours) using several concentration of $\mathrm{Na}^{+}, \mathrm{K}^{+}, \mathrm{Ca}^{2+}$, or $\mathrm{Mg}^{2+}$ and combination of all 4 ions (i.e., $0,10,20,50,100$, and $200 \mathrm{mg} / \mathrm{l})$. The adsorption capacity decreased in the presence of common cations concentration increase (Figure 6). A remarkable decrease in the adsorption capacity was not observed, when the concentration of $\mathrm{Na}^{+}, \mathrm{K}^{+}, \mathrm{Ca}^{2+}$, or $\mathrm{Mg}^{2+}$ were lower than $100 \mathrm{mg} / \mathrm{l}$ (i.e., adsorption capacity decrease was less than $20 \%$ ).

\subsection{Adsorption Kinetics}

The adsorption takes place in several stages. The adsorption kinetics determines the rate-limiting step of the adsorption from these stages, which gives the necessary 


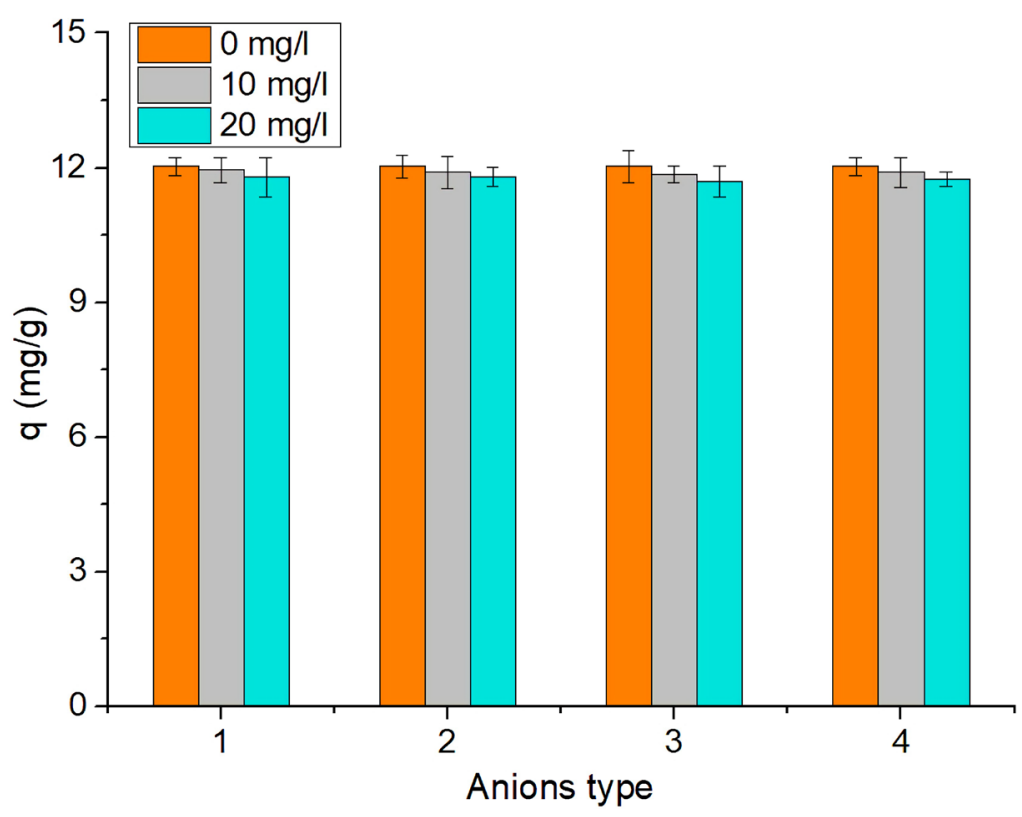

Figure 5. Effect of competitive anions on the adsorption of $\mathrm{Cr}(\mathrm{VI}) .1-\mathrm{Cl}^{-}, 2-\mathrm{SO}_{4}^{2-}, 3-$ $\mathrm{SO}_{3}^{2-}, 4-\mathrm{CH}_{3} \mathrm{COO}^{-}\left(\mathrm{pH}=3, C_{0}=50 \mathrm{mg} / \mathrm{l}, T=25^{\circ} \mathrm{C}, t=3 \mathrm{~h}\right)$.

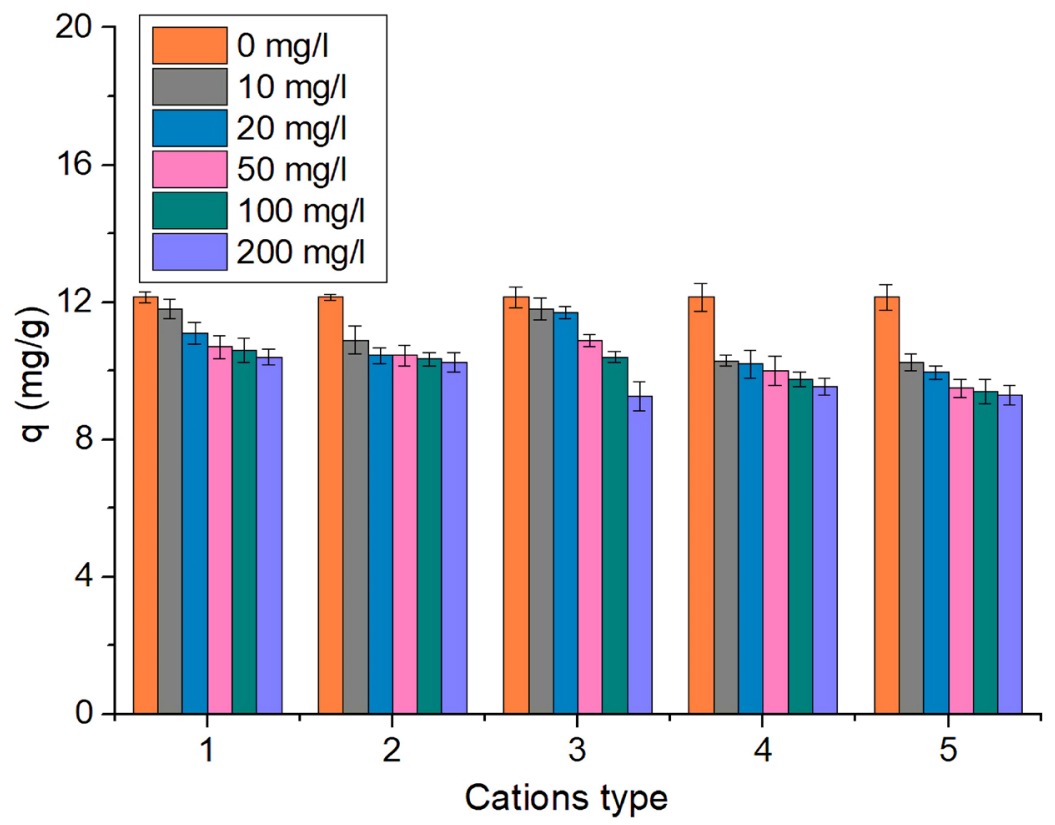

Figure 6. Effect of common cations on the adsorption of $\mathrm{Cr}(\mathrm{VI}) .1-\mathrm{Na}^{+}, 2-\mathrm{K}^{+}, 3-\mathrm{Ca}^{2+}$, $4-\mathrm{Mg}^{2+}, 5-$ combination of all 4 ions $\left(\mathrm{Na}^{+}, \mathrm{K}^{+}, \mathrm{Ca}^{2+}\right.$, and $\left.\mathrm{Mg}^{2+}\right)\left(\mathrm{pH}=3, C_{0}=50 \mathrm{mg} / \mathrm{l}, T\right.$ $=25^{\circ} \mathrm{C}, t=3 \mathrm{~h}$ ).

information for modeling and practical applications of the adsorption [14]. Mathematical models used in the kinetic study of adsorption are classified into two main groups: Reaction and diffusion models [15]. In the kinetic study of the adsorption of $\mathrm{Cr}(\mathrm{VI})$ on the modified zeolite were used a reaction model, the Lagergren first-order model and Ho second-order model [16], and intraparticle 
diffusion (Weber-Morris diffusion model) model to explain three stages of the adsorption: an external diffusion (film diffusion, transfer of adsorbate ions to surface of the adsorbent), an internal diffusion (a pore diffusion, transfer of adsorbate ions within the pores and the liquid in the pores of adsorbent) and adsorption (an attraction between the adsorbate and the active part of adsorbent) [17].

The results of the effect of time on the adsorption were analyzed by equations of the first and second-order reaction model Equation (2), (3), and intraparticle diffusion models Equation (4) to determine the kinetic parameters.

$$
\begin{gathered}
\log \left(q_{e}-q_{t}\right)=\log q_{e}-\frac{K_{1} t}{2.303} \\
\frac{t}{q_{t}}=\frac{1}{q_{e}} t+\frac{1}{K_{2} q_{e}^{2}} \\
q_{t}=K_{i d} t^{0.5}
\end{gathered}
$$

where, $q_{e}(\mathrm{mg} / \mathrm{g})$ and $q_{t}(\mathrm{mg} / \mathrm{g})$ are denote adsorption capacity at equilibrium and time $t, K_{1}\left(\mathrm{~min}^{-1}\right)$ and $K_{2}(\mathrm{~g} / \mathrm{mg} \cdot \mathrm{min})$ are the first and second order rate constants, $t(\mathrm{~min})$ is time, $K_{i d}\left(\mathrm{mg} / \mathrm{g} \cdot \mathrm{min}^{0.5}\right)$ is the rate constant of intraparticle diffusion.

The first and second-order rate constants $\left(K_{1}\right.$ and $\left.K_{2}\right)$ and intraparticle diffusion rate constant $\left(K_{i d}\right)$ were determined from the slope of the linear gradient of the plot $\log \left(q_{e}-q_{t}\right)$ versus $t, t / q_{t}$ versus $t$, and $q_{t}$ versus $t^{1 / 2}$, respectively. $q_{e}$ was calculated from the intercept of the linear gradient of the plot $\log \left(q_{e}-q_{t}\right)$ versus $t$ and $t / q_{t}$ versus $t$. The kinetic parameters of the adsorption are presented in $\mathrm{Ta}-$ ble 1 .

Table 1 shows that the regression coefficient $\left(R^{2}\right)$ value of the second-order model plot is higher than the first-order and intraparticle diffusion model plot, and the amount of calculated $q_{e}$ from the second-order model plot is relatively close to the experimental results. Therefore, second-order kinetics supports that the chemical adsorption could be the rate-limiting step of the process of the adsorption system. Based on this, the first portion of the curve in Figure 3 could be relating to film diffusion, the latter of the curve relates to pore diffusion and the second-order reaction.

Table 1. The kinetic parameters of the adsorption.

\begin{tabular}{ccccccccccc}
\hline & & \multicolumn{3}{c}{ Pseudo First-order } & \multicolumn{3}{c}{ Pseudo Second-order } & \multicolumn{2}{c}{ Intraparticle Diffusion } \\
\cline { 3 - 9 }$C_{0}$ & $q_{e}(\mathrm{exp})$ & & & & & & & \\
$(\mathrm{mg} / \mathrm{l})$ & $(\mathrm{mg} / \mathrm{g})$ & $K_{1} \cdot 10^{-2}$ & $\begin{array}{c}q_{e}(\mathrm{cal}) \\
(\mathrm{mg} / \mathrm{g})\end{array}$ & $R^{2}$ & $K_{2} \cdot 10^{-3}$ & $\begin{array}{l}q_{e} \\
(\mathrm{mg} / \mathrm{g})\end{array}$ & $R^{2}$ & $K_{i d}$ & $R^{2}$ \\
\hline 10 & 4.70 & 0.58 & 0.61 & 0.5709 & 32.5 & 4.80 & 0.9998 & 3.7351 & 0.6825 \\
25 & 9.29 & 2.63 & 3.08 & 0.9103 & 3.4 & 10.10 & 0.9937 & 4.4252 & 0.9429 \\
50 & 11.95 & 2.76 & 3.12 & 0.8161 & 4.8 & 12.54 & 0.9999 & 7.2681 & 0.9099 \\
100 & 12.90 & 3.43 & 3.66 & 0.8107 & 3.8 & 13.85 & 0.9988 & 7.3079 & 0.9053 \\
\hline
\end{tabular}


The model based on Fick's law was applied to confirm it. By this law, the relationship between adsorption capacity and time given by the following Equations (5)-(8) when adsorbent particles are assumed to be spherical with radius " $a$ " [18].

$$
\frac{q_{t}}{q_{e}}=6\left(\frac{D t}{a^{2}}\right)^{1 / 2}\left\{\pi^{-1 / 2}+\sum_{n=1}^{\infty} \operatorname{ierfc} \frac{n a}{\sqrt{D t}}\right\}-3 \frac{D t}{a^{2}}
$$

After $D$ is replaced with $D_{1}$, at a short time, Equation (5) becomes as:

$$
\frac{q_{t}}{q_{e}}=6\left(\frac{D_{1}}{\pi a^{2}}\right)^{1 / 2} t^{1 / 2}
$$

The film diffusion coefficient $D_{1}$ is found from the slope of the plot of $q_{t} / q_{e}$ versus $t^{1 / 2}$

For moderate and large times, the diffusion equation given by

$$
\frac{q_{t}}{q_{e}}=1-\frac{6}{\pi^{2}} \sum_{n=1}^{\infty} \frac{1}{n^{2}} \exp \left(\frac{-D n^{2} \pi^{2} t}{a^{2}}\right)
$$

If $D$ is replaced with $D_{2}$, at the large time the Equation (7) becomes as:

$$
\ln \left(1-\frac{q_{t}}{q_{e}}\right)=\ln \frac{6}{\pi^{2}}-\left(\frac{D n^{2} \pi^{2} t}{a^{2}}\right)
$$

The pore diffusion coefficient $D_{2}$ is obtained from the slope of the plot of $\ln (1$ $-q_{t} / q_{e}$ ) versus $t$. The values of $D_{1}$ and $D_{2}$ are presented in Table 2.

The values of the film diffusion coefficient may be in the range of $10^{-6}-10^{-8}$ $\mathrm{cm}^{2} / \mathrm{s}$ if the adsorption is controlled by the film diffusion [19]. While the value of the pore diffusion coefficient belongs to the range of $10^{-11}-10^{-13} \mathrm{~cm}^{2} / \mathrm{s}$, then the adsorption mechanism is controlled by the pore diffusion mechanism [20].

\subsection{Adsorption Thermodynamic}

The thermodynamic parameter, such as the standard Gibbs free energy change $\left(\Delta G^{0}\right)$ was evaluated by Equation (9), the standard enthalpy change $\left(\Delta H^{\oplus}\right)$ and entropy change $\left(\Delta S^{0}\right)$ were determined from Van't Hoff Equation (11), found from the slope and intercept of linear plot $\ln K_{c}$ versus $1 / T$. The results are summarized in Table 3.

$$
\begin{aligned}
\Delta G^{0} & =-R T \ln K_{c} \\
K_{c} & =\frac{C_{A e}}{C_{e}} \\
\ln K_{c} & =\frac{\Delta H^{0}}{-R T}+\frac{\Delta S^{0}}{R}
\end{aligned}
$$

where, $K_{c}$ is equilibrium constant, $C_{A e}$ is the amount of adsorbed $\mathrm{Cr}(\mathrm{VI})$ at equilibrium, $C_{e}$ is the equilibrium concentration of $\mathrm{Cr}(\mathrm{VI})$.

As shown in Table 3, the values of $\Delta G^{0}$ at the temperature range of $298-328$ $\mathrm{K}$ were obtained between -17.552 and $-18.290 \mathrm{~kJ} / \mathrm{mol}$. The negative values of $\Delta G^{0}$ are indicating that the adsorption of $\mathrm{Cr}(\mathrm{VI})$ on the modified zeolite is a 
Table 2. The film and pore diffusion coefficients of the adsorption.

\begin{tabular}{ccc}
\hline$C_{0}(\mathrm{mg} / \mathrm{l})$ & $D_{1} \cdot 10^{-13}\left(\mathrm{~cm}^{2} / \mathrm{s}\right)$ & $D_{2} \cdot 10^{-12}\left(\mathrm{~cm}^{2} / \mathrm{s}\right)$ \\
\hline 10 & 1.6 & 4.8 \\
25 & 8.8 & 4.9 \\
50 & 6.6 & 4.9 \\
100 & 6.9 & 5.2 \\
\hline
\end{tabular}

Table 3. The thermodynamic parameters of the adsorption.

\begin{tabular}{ccccc}
\hline$T(\mathrm{~K})$ & $C_{0}(\mathrm{mg} / \mathrm{l})$ & $\Delta G^{0}(\mathrm{~kJ} / \mathrm{mol})$ & $\Delta H^{\oplus}(\mathrm{kJ} / \mathrm{mol})$ & $\Delta S^{0}(\mathrm{~J} / \mathrm{mol} \cdot \mathrm{K})$ \\
\hline 298 & & -17.552 & & \\
308 & 50 & -17.771 & 8.734 & 85.933 \\
318 & & -17.797 & & \\
328 & & -18.290 & & \\
\hline
\end{tabular}

spontaneous and thermodynamically favorable process. The decrease of the value of $\Delta G^{0}$ with the increase of temperature confirms that the reaction is more spontaneous at a high temperature. A positive value of $\Delta H^{\oplus}(8.734 \mathrm{~kJ} / \mathrm{mol})$ and $\Delta S^{0}(85.933 \mathrm{~J} / \mathrm{mol} \cdot \mathrm{K})$ indicate that the process is endothermic in nature and the disorderliness of the adsorption at the solid-liquid interface (modified zeolite surface and solutions containing $\mathrm{Cr}(\mathrm{VI})$ ).

\subsection{Adsorption Isotherm}

The isotherm study was performed at the $\mathrm{pH}$ of 3 , the temperature of $45^{\circ} \mathrm{C}$ for 3 hours. The maximum adsorption capacity of the modified zeolite for $\mathrm{Cr}(\mathrm{VI})$ was $12.2 \mathrm{mg} / \mathrm{g}$ (Figure 7).

Adsorption equilibrium data were correlated to the two most commonly applied isotherm models, the Langmuir and Freundlich. The models express the relationship between adsorption capacity $\left(q_{e}\right)$ and metal concentration in solution $\left(C_{e}\right)$ at equilibrium. The Langmuir model is suitable for monolayer adsorption, assuming that the surface of the adsorbent is homogeneous, the heat of the adsorption process is constant, and no interaction between adsorbed species. This model determines the maximum adsorption capacity $(Q)$ and the coefficient $(b)$ related to binding affinity, which was calculated from the slope and intercept of the plot of $1 / q_{e}$ versus $1 / C_{e}$.

The linearized form of this model is,

$$
\frac{C_{e}}{q_{e}}=\frac{1}{Q b}+\frac{C_{e}}{Q}
$$

The Langmuir model dimensionless constant separation factor $\left(K_{L}\right)$ is defined as:

$$
K_{L}=\frac{1}{1+b C_{0}}
$$




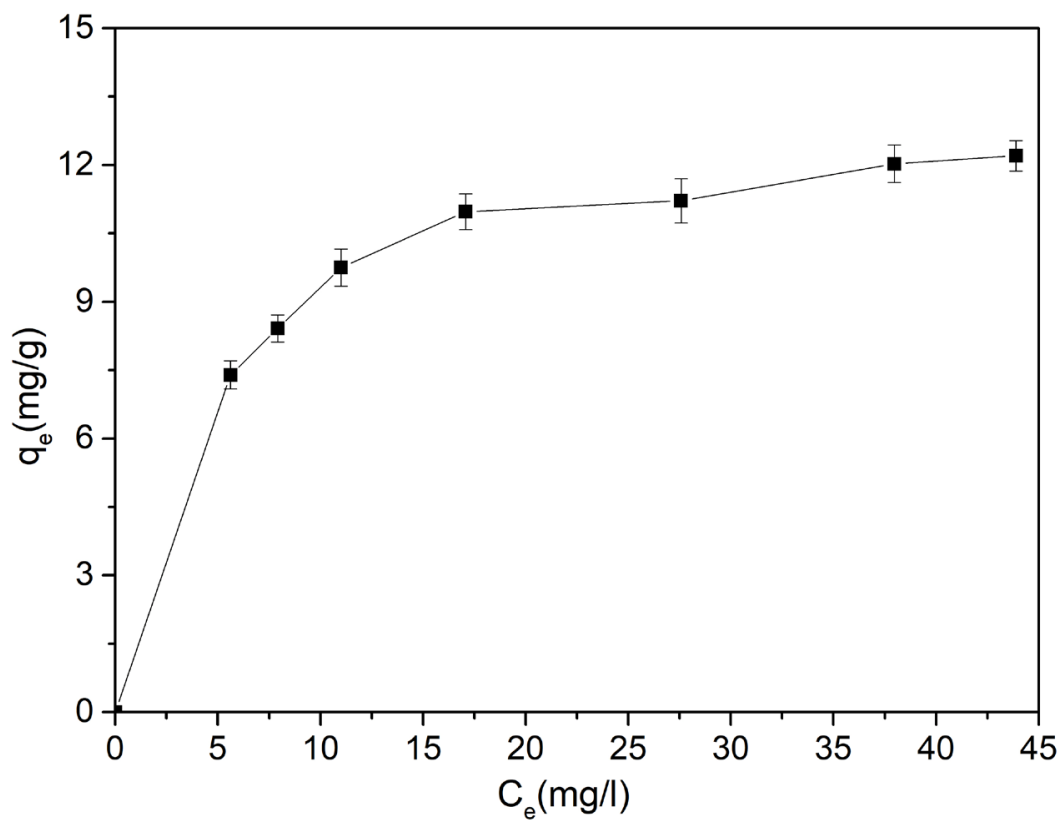

Figure 7. Isotherm curve ( $\left.\mathrm{pH}=3, t=3 \mathrm{~h}, T=45^{\circ} \mathrm{C}, n=100 \mathrm{rpm}\right)$.

$K_{L}$ indicates the shape of isotherm like, unfavorable $\left(K_{L}>1\right)$, linear $\left(K_{L}=1\right)$, favorable $\left(0<K_{L}<1\right)$, or irreversible $\left(K_{L}=0\right)$.

The Freundlich isotherm describes the heterogeneous surface energies by multilayer adsorption. This model determines parameters, indicates adsorption capacity $\left(K_{f}\right)$ and adsorption intensity $(n)$ which are found from the linear plot of $\log \left(q_{e}\right)$ versus $\log \left(C_{e}\right) . n$ values between 1 and 10 indicate beneficial adsorption [21].

A linearized form of this model is,

$$
\log q_{e}=\log K_{f}+n \log C_{e}
$$

The constants of these models are summarized in Table 4.

Table 4 shows that the adsorption may be followed by the Langmuir isotherm model. It was confirmed by the relatively high value of the correlation coefficient $\left(R^{2}=0.9894\right)$ and the value of the Langmuir model dimensionless constant separation factor $\left(K_{L}=0.084\right)$.

Table 5 shows the results of studies using zeolite as an adsorbent to remove $\mathrm{Cr}(\mathrm{VI})$ from the aqueous solution.

\subsection{Desorption and Regeneration of Modified Zeolite Adsorbent}

As shown in Figure 8(a), the lowest amount of the desorption efficiency of $\mathrm{Cr}$ was determined with $0.05 \mathrm{M} \mathrm{HNO}_{3}$. Therefore, the solution $\mathrm{HNO}_{3}$ with the concentration of $0.05 \mathrm{M}$ was not used for the regeneration experiment.

The results of desorption efficiency of $\mathrm{Cr}$ with regenerated modified zeolite adsorbent for five cycles are shown in Figure 8(b). The result indicates that the desorption efficiency of $\mathrm{Cr}$ decreased with increasing concentration of desorbing agent from $0.1 \mathrm{M}$ to $0.4 \mathrm{M}$. The sorption efficiency was $43.0 \%, 28.9 \%$ and, $22.3 \%$ 
Table 4. Isotherm constant.

\begin{tabular}{ccc}
\hline Isotherm Model & Isotherm Constant \\
\hline & $Q(\mathrm{mg} / \mathrm{g})$ & 13.532 \\
Langmuir & $b(\mathrm{l} / \mathrm{mg})$ & 0.216 \\
& $K_{L}$ & 0.084 \\
$R^{2}$ & 0.9894 \\
\hline \multirow{2}{*}{ Freundlich } & $K_{f}(\mathrm{l} / \mathrm{g})$ & 0.723 \\
& $n$ & 0.230 \\
& $R^{2}$ & 0.9302 \\
\hline
\end{tabular}

Table 5. Comparison of maximum sorption capacity of modified zeolite with other adsorbents.

\begin{tabular}{clcc}
\hline № & \multicolumn{1}{c}{ Adsorbents } & $\boldsymbol{q}, \mathbf{( m g / g )}$ & Ref \\
\hline $\mathbf{1}$ & Amino functionalized hydrophobic zeolite & 9.490 & {$[22]$} \\
$\mathbf{2}$ & Zeolitic imidazolate framework-67 microcrystals & 5.880 & {$[23]$} \\
$\mathbf{3}$ & Surfactant-modified Iranian zeolite & 4.389 & {$[24]$} \\
$\mathbf{4}$ & Synthetic zeolite & 1.790 & {$[25]$} \\
$\mathbf{5}$ & Indonesia (Ende-Flores) natural zeolite & 4.365 & {$[26]$} \\
$\mathbf{6}$ & Zeolite treated with NaCl & 3.230 & {$[27]$} \\
$\mathbf{7}$ & Natural clinoptilolite zeolite & 10.420 & {$[28]$} \\
$\mathbf{8}$ & Zeolite 13x & 3.929 & {$[29]$} \\
$\mathbf{9}$ & Organo-modified zeolitic material & 2.270 & {$[30]$} \\
$\mathbf{1 0}$ & Mongolian zeolite, modified with APTES & 13.532 & In this study \\
\hline
\end{tabular}

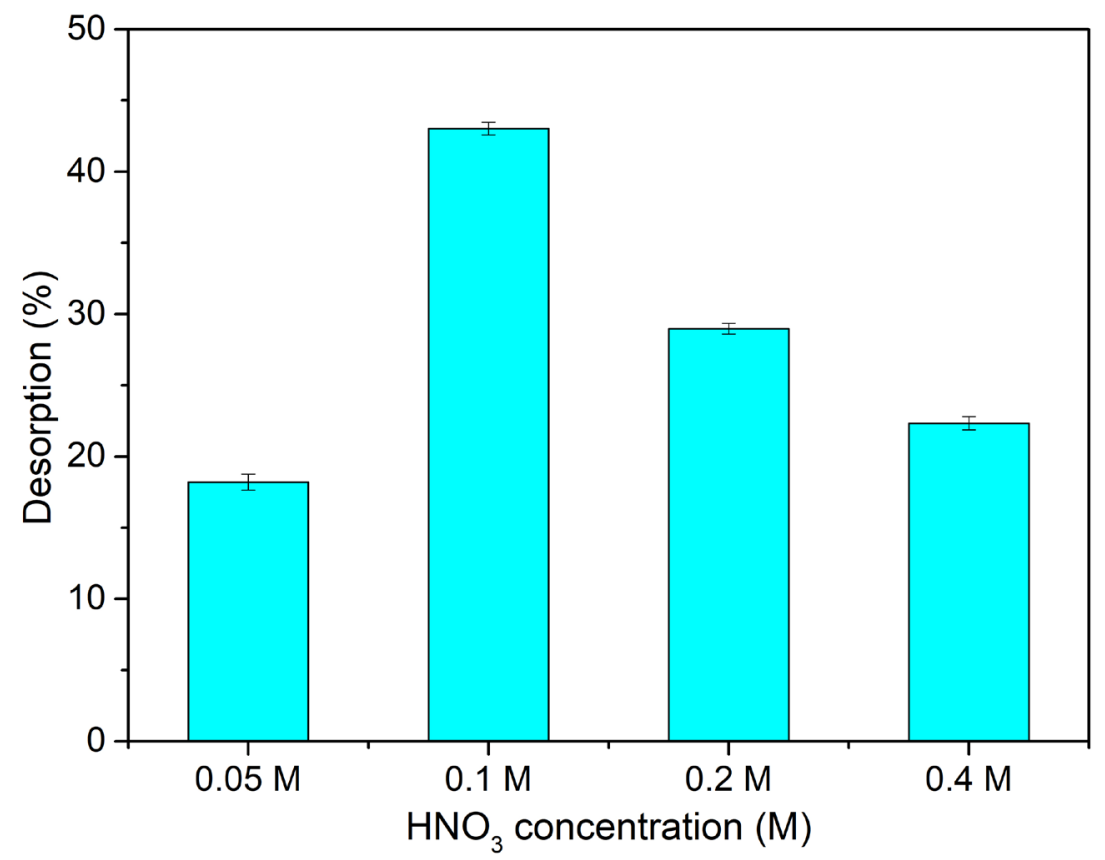

(a) 


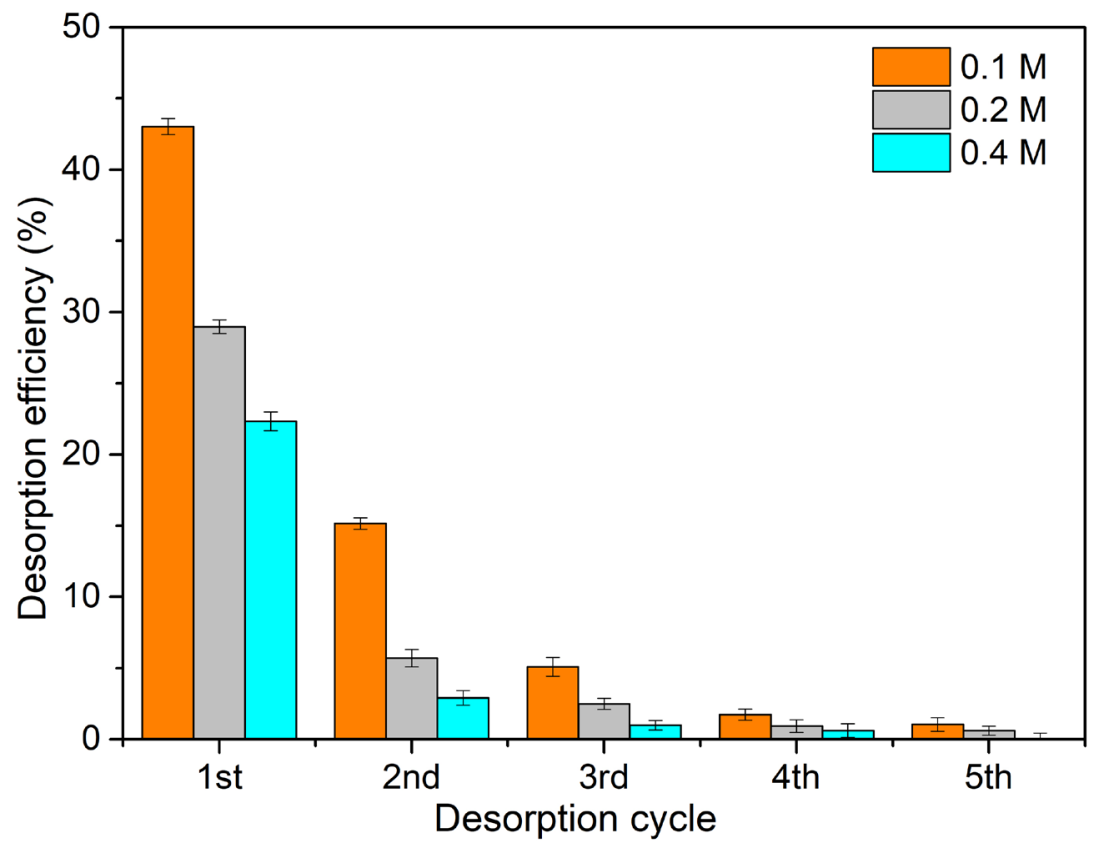

(b)

Figure 8. Desorption of Cr from modified zeolite (a) and regeneration of modified zeolite adsorbent (b).

for the first cycle of the regeneration. However, it was decreased consequently for the 2, 3, 4, and 5th cycles. This result indicates that further investigation on desorption and regeneration study needed.

\subsection{Instrumental Analysis}

The results of the instrumental analysis such as XRD (Figure 9), EDS (Figure 10), SEM (Figure 11), BET (Table 6), and FT-IR (Figure 12) of natural zeolite, modified zeolite are compared below.

XRD pattern (Figure 9) showed that natural zeolite peaks appear at a range of $2 \theta$ angle values of $10.13 \theta(100), 11.43 \theta(200), 15.38 \theta(220), 17.49 \theta(111), 19.34 \theta$ (131), $22.74 \theta$ (400), $25.22 \theta$ (312), $26.58 \theta$ (222), $28.48 \theta$ (422), $30.27 \theta$ (132), $32.31 \theta$ (530), $36.06 \theta$ (351) and $37.26 \theta$ (441) [31] [32] [33] [34] [35]. These peaks indicate that the natural zeolite is dominated by clinoptilolite-type zeolites. Clinoptilolitetype zeolites have the general formula $(\mathrm{Na}, \mathrm{K}, \mathrm{Ca})_{2-3} \mathrm{Al}_{3}\left(\mathrm{Al}, \mathrm{Si}_{2} \mathrm{Si}_{13} \mathrm{O}_{36} \cdot 12 \mathrm{H}_{2} \mathrm{O}\right.$.

No significant change was observed on the diffraction peak position of the modified zeolite, and the same diffraction peaks were found in natural and modified zeolites. These are indicating that the structure of the natural zeolite is maintained after the modification. However, after the modification, the intensities of most peaks were decreased, indicating the zeolite surface may be functionalized by APTES. In other words, the decrease of the peak intensities confirms that the modification and adsorption of $\mathrm{Cr}(\mathrm{VI})$ have been done successfully. According to the results of the elemental analysis of the natural zeolite (Figure $10(\mathrm{a}))$, the ratio of $\mathrm{Si} / \mathrm{Al}(5.9 \mathrm{~mol} / \mathrm{mol})$ and the content of $\mathrm{K}(9.1 \%)$ indicate that 


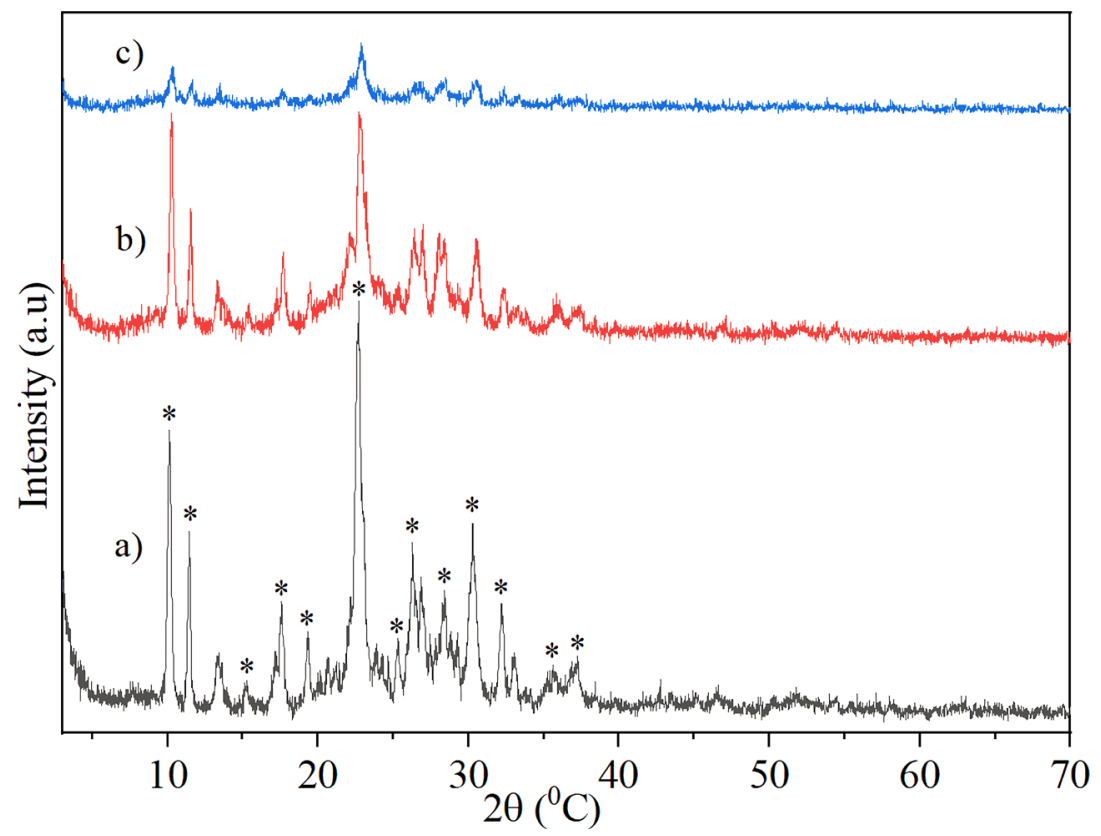

Figure 9. XRD pattern of natural zeolite (a), modified zeolite before (b) andafter the adsorption.

$n$

(a)

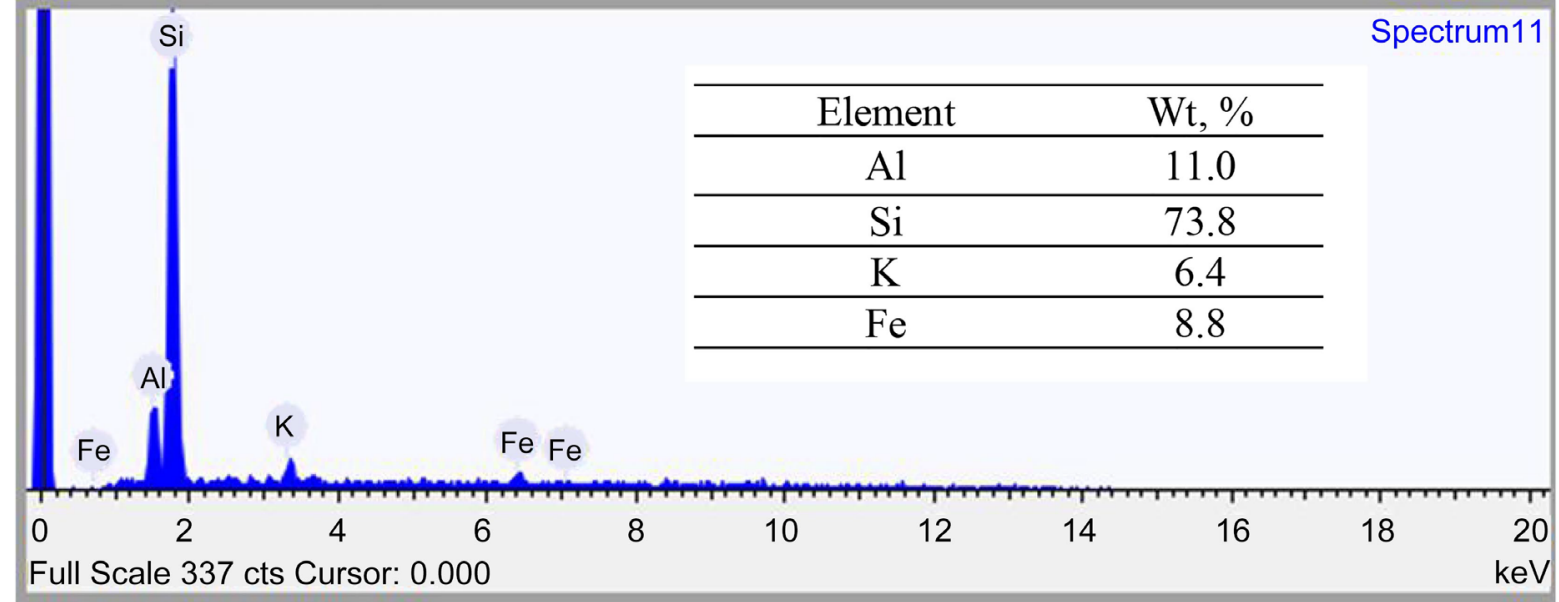

(b) 


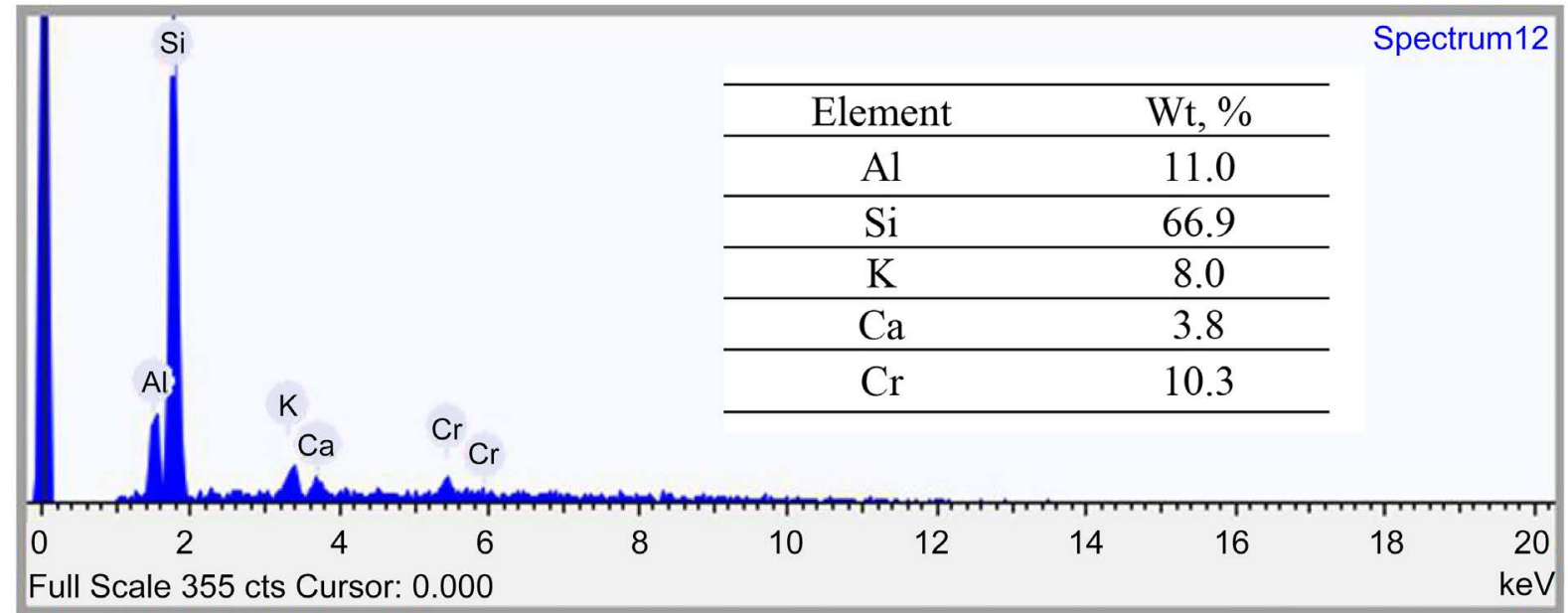

(c)

Figure 10. Elemental analysis. ((a) Natural zeolite; (b) Modified zeolite before the adsorption; (c) Modified zeolite after the adsorption).

Table 6. The surface property of natural, pretreated, and modified zeolite.

\begin{tabular}{cccc}
\hline Sample & BET Surface Area $\left(\mathrm{m}^{2} / \mathrm{g}\right)$ & Pore Volume $\left(\mathrm{cm}^{3} / \mathrm{g}\right)$ & Pore Size $(\mathrm{nm})$ \\
\hline Natural zeolite & 22.79 & 0.058 & 10.188 \\
Pretreated zeolite & 18.28 & 0.053 & 11.597 \\
Modified zeolite & 9.06 & 0.035 & 15.243 \\
\hline
\end{tabular}

the Tsagaantsav deposit is dominated by clinoptilolite-type minerals and thermally stable [11] [34]. After the modification of natural zeolite, the silicon content increased from $66.2 \%$ to $73.8 \%$, indicating the presence of silicon organic monomer with amine groups (3-aminopropyltrimethoxysilane) (Figure 10(b)). And after the adsorption of $\mathrm{Cr}(\mathrm{VI}), 10.3 \%$ chromium was detected (Figure 10(c)).

SEM images of the natural and modified zeolite before and after adsorption of $\mathrm{Cr}(\mathrm{VI})$ are shown in Figure 11. Figure 11(a) and Figure 11(b) are shown that no significant change in the morphology of the zeolite crystals after their modification with APTES.

It confirmed that the structure of the natural zeolite was not destroyed much in the modification and natural zeolite surface functionalized by APTES. This result is consistent with those of the XRD analysis. But changes were observed in the morphology of the modified zeolite after the adsorption of $\mathrm{Cr}(\mathrm{VI})$ shown in Figure 11(c).

The surface property of natural, pretreated, and modified zeolite was analyzed by $\mathrm{N}_{2}$ adsorption, and the result of the adsorption/desorption isotherm is shown in Table 6. The BET surface areas of natural, pretreated, and modified zeolite were $22.79,18.28$, and $9.06 \mathrm{~m}^{2} / \mathrm{g}$, respectively and the corresponding pore volumes were $0.058,0.053$, and $0.035 \mathrm{~cm}^{3} / \mathrm{g}$. The average pore diameter of natural zeolite increased after the modification from $10.188 \mathrm{~nm}$ to $15.243 \mathrm{~nm}$. The remarkable decrease in the BET surface area and pore volume after the modification 


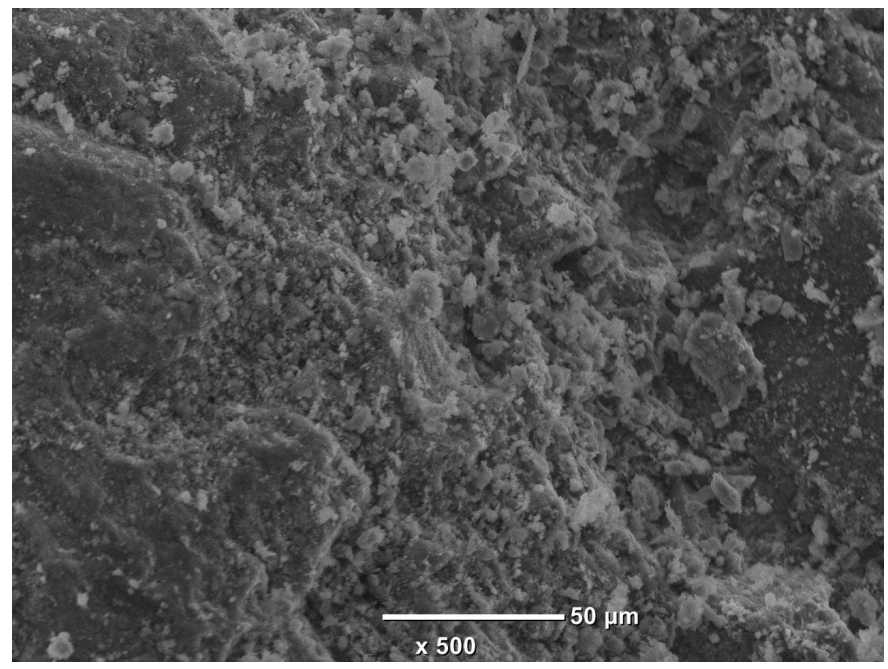

(a)

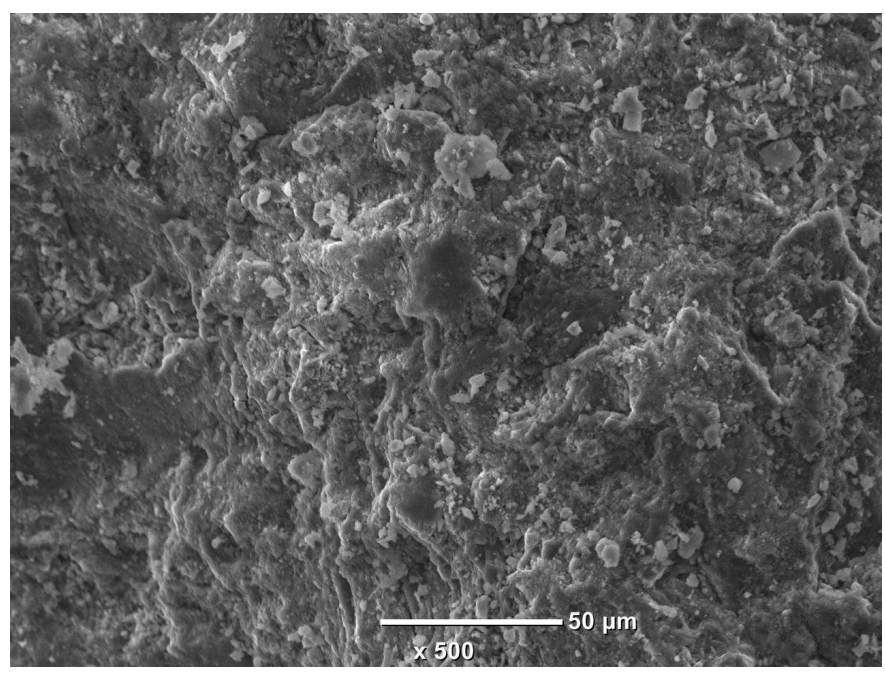

(b)

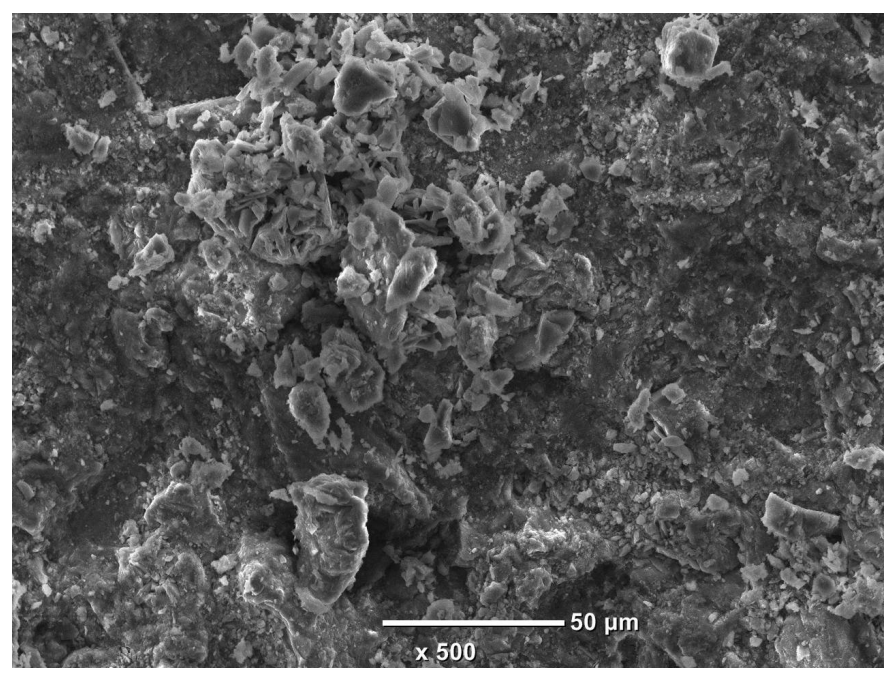

(c)

Figure 11. SEM images of the natural (a) andmodified zeolite before (b) and after (c) adsorption of $\mathrm{Cr}(\mathrm{VI})$. 


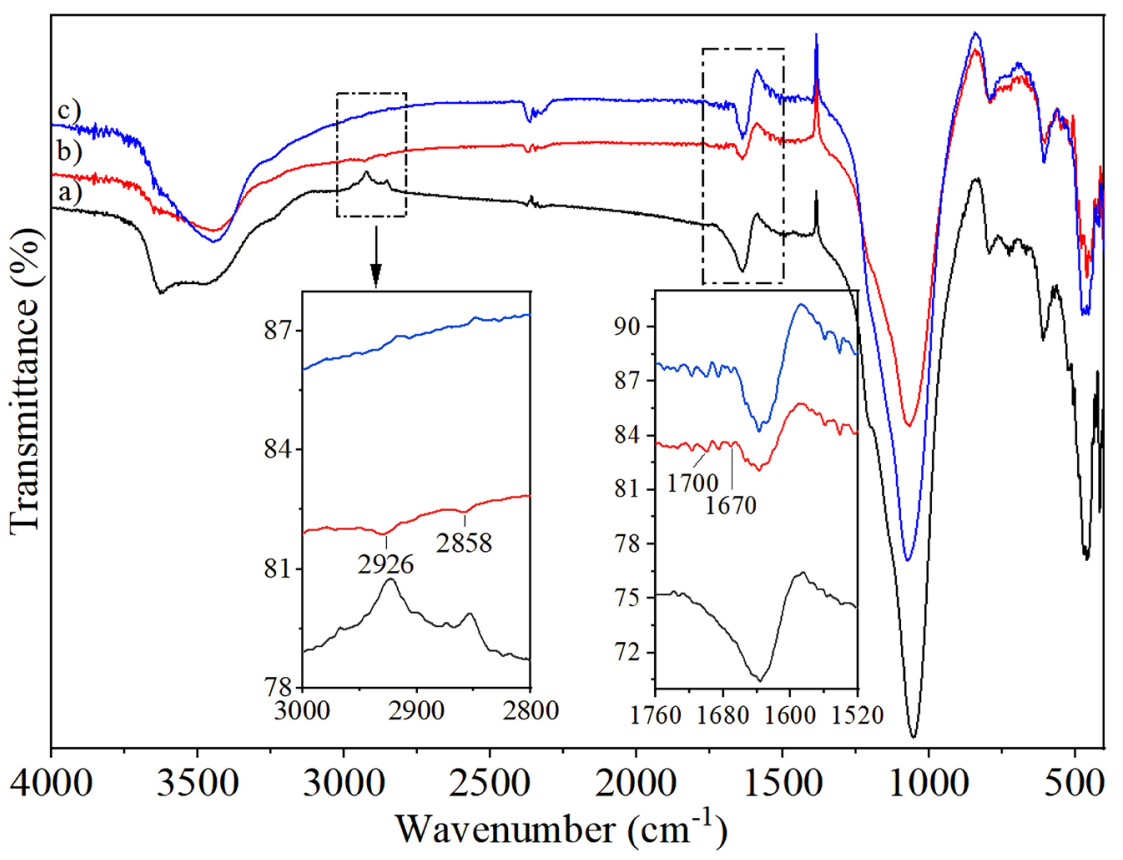

Figure 12. FT-IR spectra of the natural (a) and modified zeolite (b) and after (c) adsorption of $\mathrm{Cr}(\mathrm{VI})$.

indicates that APTES molecules loaded into the surface of the zeolite. Shaogang Liu et al. [36] reported similar results on surface properties of modified zeolite.

The FT-IR spectra of the natural and modified zeolite before and after adsorption of $\mathrm{Cr}(\mathrm{VI})$ are shown in Figure 12. Typical peaks of natural zeolite were found at $3620 \mathrm{~cm}^{-1}$ (Si-OH), $3463 \mathrm{~cm}^{-1}(\mathrm{OH})$ [35], $1642 \mathrm{~cm}^{-1}$ (corresponding to water molecules associated with the cations in zeolite structure) [25] [37]. The peaks corresponding to $\mathrm{Si}-\mathrm{O}, \mathrm{Al}-\mathrm{O}$ bond in the $\mathrm{SiO}_{4}$ and $\mathrm{AlO}_{4}$ tetrahedral at $1052 \mathrm{~cm}^{-1}$, the peaks corresponding to $\mathrm{Si}-\mathrm{O}-\mathrm{Si}$ and $\mathrm{Al}-\mathrm{O}-\mathrm{Al}$ bond at 459 and 796 $\mathrm{cm}^{-1}$ were detected [25]. After modification, the intensities of the peaks at 3620 and $3463 \mathrm{~cm}^{-1}$ were decreased, and new peaks with low intensity were detected. For example, at 2926 and $2858 \mathrm{~cm}^{-1}\left((v \mathrm{C}-\mathrm{H}) \mathrm{CH}_{3}\right.$ and $\left.(v \mathrm{C}-\mathrm{H}) \mathrm{CH}_{2}\right)$ [38], at 1700 and $1670 \mathrm{~cm}^{-1}(\mathrm{NCN})$, at 1561 and $1540 \mathrm{~cm}^{-1}\left(-\mathrm{NH}_{2}\right)$ [38] [39]. These peaks are corresponding to the group of silicon-organic monomer $\left(\mathrm{Si}_{(}\left(\mathrm{CH}_{2}\right)_{3} \mathrm{NH}_{2}\right)$, detected with low intensity due to low concentrated solution of APTES were taken for the modification [37].

The peaks relating to $\mathrm{Si}-\mathrm{O}-\mathrm{Si}, \mathrm{Al}-\mathrm{O}-\mathrm{Al}, \mathrm{Si}-\mathrm{O}$, and $\mathrm{Al}-\mathrm{O}$ did not shift but their intensity was decreased. These all changes confirm that natural zeolites have been modified with APTES. After the adsorption, the intensity of the peak at $3463 \mathrm{~cm}^{-1}$ was increased, and at $2926 \mathrm{~cm}^{-1}, 2858 \mathrm{~cm}^{-1}(\mathrm{lC}-\mathrm{H})$ were decreased. The intensities of the peaks at $1700,1670 \mathrm{~cm}^{-1}(\mathrm{LCN})$, and $1561,1540 \mathrm{~cm}^{-1}$ $\left(-\mathrm{NH}_{2}\right)$ were increased.

\section{Conclusion}

The modification of the natural zeolite of the Tsagaantsav deposit of Mongolia 
has been done successfully, and the maximum adsorption capacity for $\mathrm{Cr}(\mathrm{VI})$ was $13.532 \mathrm{mg} / \mathrm{g}$. The kinetics result has shown that the rate-limiting step of adsorption of $\mathrm{Cr}(\mathrm{VI})$ on the modified zeolite is the second-order reaction. The results of thermodynamics and isotherm studies determined that the adsorption is spontaneous, thermodynamically favorable, endothermic, and followed the Langmuir model. The adsorption of $\mathrm{Cr}(\mathrm{VI})$ on the modified zeolite took place in the following steps: 1) Binding of $\mathrm{HCrO}_{4}^{-}$to the protonated surface of the adsorbent by electrostatic attraction. 2) Reduction of $\mathrm{Cr}(\mathrm{VI})$ to $\mathrm{Cr}(\mathrm{III})$. The amino group may have played an essential role in this process as the reducing reagent. 3) Formation of a complex compound of $\mathrm{Cr}(\mathrm{III})$.

\section{Acknowledgements}

This work was supported by the "Higher Engineering Education Development" (M-JEED) Project. The authors are grateful to the staff of the Faculty of Engineering in Niigata University for permitting the use of XRD, FT-IR, SEM, BET and for giving helpful advice in measurement.

\section{Conflicts of Interest}

The authors declare no conflicts of interest regarding the publication of this paper.

\section{References}

[1] Mishra, S., Bharagava, R.N., Yadav, A., Zainith, S. and Chowdhary, P. (2019) Heavy Metal Contamination: An Alarming Threat to Environment and Human Health. In: Sobti, R., Arora, N. and Kothari, R., Eds., Environmental Biotechnology: For Sustainable Future, Springer, Singapore, 103-125. https://doi.org/10.1007/978-981-10-7284-0_5

[2] Momodu, M.A. and Anyakora, C.A. (2010) Heavy Metal Contamination of Ground Water: The Surulere Case Study. Research Journal Environmental and Earth Sciences, 2, 39-43.

[3] Li, X., Poon, C. and Liu, P.S. (2001) Heavy Metal Contamination of Urban Soils and Street Dusts in Hong Kong. Applied Geochemistry, 16, 1361-1368. https://doi.org/10.1016/S0883-2927(01)00045-2

[4] Sun, H., Brocato, J. and Costa, M. (2015) Oral Chromium Exposure and Toxicity. Current Environmental Health Reports, 2, 295-303. https://doi.org/10.1007/s40572-015-0054-Z

[5] Chakraborty, R., Asthana, A., Singh, A.K., Jain, B. and Susan, A.B.H. (2020) Adsorption of Heavy Metal Ions by Various Low-Cost Adsorbents: A Review. International Journal of Environmental Analytical Chemistry. https://doi.org/10.1080/03067319.2020.1722811

[6] Bolortamir, T.S. and Egashira, R. (2008) Removal of Hexavalent Chromium from Model Tannery Wastewater by Adsorption Using Mongolian Natural Zeolite. Journal of Chemical Engineering of Japan, 41, 1003-1009. https://doi.org/10.1252/jcej.08we069

[7] Egashira, R., Tanabe, S. and Habaki, H. (2012) Removal of Heavy Metals from Model Mine Waste Water by Adsorption Using Mongolian Natural Zeolites. Proce- 
dia Engineering, 42, 49-57. https://doi.org/10.1016/j.proeng.2012.07.394

[8] Dyer, A., Chimedtsogzol, A., Campbell, L. and Williams, C. (2006) Uptake of Caesium and Strontium Radioisotopes by Natural Zeolites from Mongolia. Microporous and Mesoporous Materials, 95, 172-175.

https://doi.org/10.1016/j.micromeso.2006.05.013

[9] Munkhbat, D., Shiomori, K. and Ochirkhuyag, B. (2016) Characterization of Mongolian Natural Minerals and Their Application for Heavy Metal Adsorbent. Mongolian journal of Chemistry, 17, 50-54. https://doi.org/10.5564/mjc.v17i43.747

[10] Huang, H., Wang, Y., Zhang, Y., Niu, Z. and Li, X. (2020) Amino-Functionalized Graphene Oxide for $\mathrm{Cr}(\mathrm{VI}), \mathrm{Cu}(\mathrm{II}), \mathrm{Pb}(\mathrm{II})$ and $\mathrm{Cd}(\mathrm{II})$ Removal from Industrial Wastewater. Open Chemistry, 18, 97-107. https://doi.org/10.1515/chem-2020-0009

[11] Akdeniz, Y. and Ülkü, S. (2008) Thermal Stability of Ag-Exchanged Clinoptilolite Rich Mineral. Journal of Thermal Analysis and Calorimetry, 94, 703-710. https://doi.org/10.1007/s10973-008-9358-7

[12] Pang, M., Kano, N. and Imaizumi, H. (2015) Adsorption of Chromium(VI) from Aqueous Solution Using Zeolite/Chitosan Hybrid Composite. Journal of Chemistry, Chemical Engineering, 9, 433-441. https://doi.org/10.17265/1934-7375/2015.07.001

[13] Pomazkina, O.I., Filatova, E.G. and Pozhidaev, Y.N. (2017) Adsorption of Ni(II), Cu(II), and $\mathrm{Zn}(\mathrm{II})$ Ions by Natural Alumosilicate Modified with $N, N$-bis(3-triethoxysilylpropyl) Thiocarbamide. Protection of Metals and Physical Chemistry of Surfaces, 53, 416-421. https://doi.org/10.1134/S2070205117030182

[14] González, M.A., Pavlovic, I. and Barriga, C. (2015) $\mathrm{Cu}(\mathrm{II}), \mathrm{Pb}(\mathrm{II})$ and $\mathrm{Cd}(\mathrm{II})$ Sorption on Different Layered Double Hydroxides. A Kinetic and Thermodynamic Study and Competing Factors. Chemical Engineering Journal, 269, 221-228.

https://doi.org/10.1016/j.cej.2015.01.094

[15] Qiu, H., Lv, L., Pan, B.C., Zhang, Q.J., Zhang, W.M. and Zhang, Q.X. (2009) Critical Review in Adsorption Kinetic Models. Journal of Zhejiang University-SCIENCE A, 10, 716-724. https://doi.org/10.1631/jzus.A0820524

[16] Ho, Y.S., Porter, J.F. and McKay, G. (2002) Equilibrium Isotherm Studies for the Sorption Divalent Metal Ions onto Peat: Copper, Nickel and Lead Single Component Systems. Water, Air, and Soil Pollution, 141, 1-33.

https://doi.org/10.1023/A:1021304828010

[17] Weber, W.J. and Morris, J.C. (1963) Kinetics of Adsorption on Carbon Solution. American Society of Civil Engineers, 89, 31-59.

https://doi.org/10.1061/JSEDAI.0000430

[18] Karthikeyan, T., Rajgopal, S. and Miranda, L.R. (2015) Chromium Adsorption from Aqueous Solution by Hevea brasilinesis Sawdust Activated Carbon. Journal of Hazardous Materials, 124, 192-199. https://doi.org/10.1016/j.jhazmat.2005.05.003

[19] Michelson, L.D., Gideon, P.G., Pace, E.G. and Kutal, L.H. (1975) Removal of Soluble Mercury from Wastewater by Complexing Techniques. Department of Chemical Engineering, Virginia Polytechnic Institute and State University, Blacksburg, VA.

[20] Mckay, G. and Poots, V.J. (1980) Kinetics and Diffusion Processes in Color Removal from Effluent Using Wood as an Adsorbent. Journal of Chemical Technology and Biotechnology, 30, 279-292. https://doi.org/10.1002/jctb.503300134

[21] Salam, M. and Munekage, Y. (2009) Removal of Arsenic from Aqueous Solution Using Silica Ceramic: Adsorption Kinetic and Equilibrium Studies. International Journal of Environmental Research, 3, 13-22. 
[22] Wang, C.H., Leng, S.Z., Xu, Y., Tian, Q., Zhang, X., Cao, L. and Huang, J. (2018) Preparation of Amino Functionalized Hydrophobic Zeolite and Its Adsorption Properties for Chromate and Naphthalene. Minerals, 8, 145. https://doi.org/10.3390/min8040145

[23] Li, X.Y., Gao, X.Y., Ai, L.H. and Jiang, J. (2015) Mechanistic Insight into the Interaction and Adsorption of $\mathrm{Cr}(\mathrm{VI})$ with Zeolitic Imidazolate Framework-67 Microcrystals from Aqueous Solution. Chemical Engineering Journal, 274, 238-246. https://doi.org/10.1016/j.cej.2015.03.127

[24] Agari, G. and Ramavandi, B. (2013) Cr(VI) Adsorption from Aqueous Solution Using a Surfactant-Modified Iranian Zeolite: Characterization, Optimization, and Kinetic Approach. Desalination and Water Treatment, 51, 31-33. https://doi.org/10.1080/19443994.2013.769928

[25] Baracat, M.A. (2008) Adsorption of Heavy Metals from Aqueous Solutions on Synthetic Zeolite. Research Journal of Environmental Sciences, 2, 13-22.

https://doi.org/10.3923/rjes.2008.13.22

[26] Neolaka, Y.A., Supriyanto, G. and Kusuma, H.S. (2018) Adsorption Performance of Cr(VI)-Imprinted Poly(4-VP-co-MMA) Supported on Activated Indonesia (EndeFlores) Natural Zeolite Structure for $\mathrm{Cr}(\mathrm{VI})$ Removal from Aqueous Solution. Journal of Environmental Chemical Engineering, 6, 3436-3443. https://doi.org/10.1016/j.jece.2018.04.053

[27] Babel, S. and Kurniawan, T.A. (2003) A Research Study on Cr(VI) Removal from Contaminated Wastewater Using Natural Zeolite. Journal of Ion Exchange, 14, 289-292. https://doi.org/10.5182/jaie.14.Supplement_289

[28] Jorfi, S., Ahmadi, M.J. and Pourfadakari, S. (2017) Adsorption of Cr(VI) by Natural Clinoptilolite Zeolite from Aqueous Solutions: Isotherms and Kinetics. Polish Journal of Chemical Technology, 19, 106-114. https://doi.org/10.1515/pjct-2017-0056

[29] Jin, Y., Wu, Y. and Wu, Y. (2015) Adsorption Behavior of Cr(VI), Ni(II), and Co(II) onto Zeolite 13x. Desalination and Water Treatment, 54, 511-524. https://doi.org/10.1080/19443994.2014.883333

[30] Warchol, J., Misaelides, P., Petrus, R. and Zamboulis, D. (2006) Preparation and Application of Organo-Modified Zeolitic Material in the Removal of Chromates and Iodides. Journal of Hazardous Materials, 137, 1410-1416. https://doi.org/10.1016/j.jhazmat.2006.04.028

[31] Al-Oud, S.S., Ghoneim, A.M., Nadeem, M.A. and Harbi, S.A. (2015) Application Efficiency of Clinoptilolite Natural Zeolite for $\mathrm{Pb}^{2+}$ and $\mathrm{Cu}^{2+}$ Removal from Wastewater. Wulfenia, 22, 320-332.

[32] Waluyo, J. and Richards, T. (2017) Makertihartha IGBN, Susanto H. Modification of Natural Zeolite as a Catalyst for Steam Reforming of Toluene. ASEAN Journal of Chemical Engineering, 17, 37-45.

[33] Ruíz-Baltazar, A., Esparza, R., Gonzalez, M., Rosas, G. and Pérez, R. (2015) Preparation and Characterization of Natural Zeolite Modified with Iron Nanoparticles. Journal of Nanomaterials, 2015, Article ID: 364763. https://doi.org/10.1155/2015/364763

[34] Mansouri, N., Rikhtegar, N., Panahi, H.A., Atabi, F. and Shahraki, B.K. (2013) Porosity, Characterization and Structural Properties of Natural Zeolite-Clinoptilolite as a Sorbent. Environment Protection Engineering, 39, 39-152. https://doi.org/10.37190/epe130111

[35] Moshoeshoe, M., Nadiye-Tabbiruka, M.S. and Obuseng, V. (2017) A Review of the 
Chemistry, Structure, Properties and Applications of Zeolites. American Journal of Materials Science, 7, 196-221.

[36] Liu, S., Ding, Y., Li, P., Diao, K., Tan, X., Lei, F., Zhan, Y., Li, Q., Huang, B. and Huang, Z. (2014) Adsorption of the Anionic Dye Congo Red from Aqueous Solution onto Natural Zeolites Modified with N,N-Dimethyl Dehydroabietylamine Oxide. Rasayan Journal of Chemistry, 248, 135-144.

https://doi.org/10.1016/j.cej.2014.03.026

[37] Yang, Y., Yang, J., Du, Y., Li, C., Wei, K., Lu, J., Chen, W. and Yang, L. (2019) Preparation and Characterization of Cationic Water-Soluble Pillar[5]arene-Modified Zeolite for Adsorption of Methyl Orange. American Chemical Society, 4, 17741-17751. https://doi.org/10.1021/acsomega.9b02180

[38] Pena-Alonzo, R., Rubio, F. and Rubio, J. (2007) Study of the Hydrolysis and Condensation of $\gamma$-Aminopropyltriethoxysilane by FT-IR Spectroscopy. Journal of Material Science, 42, 595-603. https://doi.org/10.1007/s10853-006-1138-9

[39] Berktas, I., Ghafar, A.N., Fontana, P., Caputcu, A., Menceloglu, Y. and Okan, B.S. (2020) Facile Synthesis of Graphene from Waste Tire/Silica Hybrid Additives and Optimization Study for the Fabrication of Thermally Enhanced Cement Grouts. Molecules, 25, 886. https://doi.org/10.3390/molecules25040886 